\title{
INFLUÊNCIA DA FOLGA FINANCEIRA NO RETORNO POR AÇÕES EM EMPRESAS BRASILEIRAS E CHILENAS
}

\author{
INFLUENCE OF FINANCIAL SLACK IN STOCK RETURNS IN \\ BRAZILIAN AND CHILEAN COMPANIES
}

\author{
Data de submissão: 25-04-2016 \\ Aceite: 13-11-2016 \\ Catia Heinzen ${ }^{1}$ \\ Filipy Furtado Sell ${ }^{2}$ \\ Tarcisio Pedro Silva ${ }^{3}$
}

\section{RESUMO}

Devido ao fato de o mercado de ações ser instável e passar por constantes turbulências, o controle do desempenho organizacional torna-se indispensável para uma gestão sustentável. As empresas necessitam, assim, de estratégias que melhorem seus desempenhos, tornando-as mais competitivas. Desse modo, a presente pesquisa destina-se à análise da influência da folga financeira no retorno por ações nas empresas brasileiras e chilenas que fazem parte do IBrX-50 e IPSA-40, respectivamente. Para o alcance desse objetivo, realizou-se uma pesquisa descritiva, documental e quantitativa. $O$ período analisado compreendeu cinco anos (2010 a 2014), e a amostra final foi composta de 27 empresas chilenas e 25 empresas brasileiras. Todos os dados foram tabulados em planilha eletrônica e analisados por meio do software SPSS. Os resultados evidenciam que as empresas brasileiras possuem menos folga financeira do que as empresas chilenas. No entanto, as empresas do Brasil apresentaram melhores índices de retornos por ações em comparação com as empresas do Chile, o que sugere que nem sempre possuir maior folga resultará em um melhor retorno de mercado. Os dados desta pesquisa indicam, também, que, considerando-se o modelo utilizado e o período analisado, não existe influência da folga financeira no retorno por ações tanto nas empresas brasileiras quanto nas empresas chilenas.

Palavras-chave: Folga financeira. Retorno de ações. Brasil. Chile.

\footnotetext{
1 Possui graduação em Ciências Contábeis pela Universidade para o Desenvolvimento do Alto Vale do Itajaí, UNIDAVI e mestrado em andamento em Ciências Contábeis pela Fundação Universidade Regional de Blumenau, FURB. Rio do Sul. Santa Catarina. Brasil. E-mail: catiaheinzen@hotmail.com

2 Possui graduação em Ciências Contábeis pelo Instituto de Ensino Superior da Grande Florianópolis, IES mestrado em andamento em Ciências Contábeis pela Fundação Universidade Regional de Blumenau, FURB. Rio do Sul. Santa Catarina. Brasil. E-mail: filipysell@ hotmail.com

3 Possui graduação em Ciências Contábeis pela Fundação Universidade Regional de Blumenau, FURB, mestrado em Ciências Contábeis pela Fundação Universidade Regional de Blumenau, FURB e doutorado em Ciências Contábeis pela Fundação Universidade Regional de Blumenau, FURB. Blumenau. Santa Catarina. Brasil. E-mail: tarcisio@furb.br
} 


\section{ABSTRACT}

Due the stock market is unstable and undergo constant turmoil, organizational control performance becomes indispensable for a sustainable management. Companies need strategies to improve their performance making them more competitive. Thus, the research is intended to analyze the influence of financial slack in return for shares in the Brazilian and Chilean companies that are part of the IBrX-50 and IPSA-40 respectively. To reach the goal, there was a descriptive, documentary, with a quantitative approach. The analyzed period was five years (2010-2014), the final sample was 27 Chilean companies and 25 Brazilian companies. All data were tabulated in a spreadsheet and analyzed by SPSS software. The results showed that Brazilian companies have less financial slack in relation to Chilean companies, however, the companies of Brazil showed returns of indexes for better action compared to companies of Chile, suggesting that not always have more financial slack, will as a result a better market return. The survey data also indicated that there is no influence of financial slack in return for shares in both Brazilian companies as well as Chilean companies by the model and the period analyzed.

Keywords: Financial slack. Stock returns. Brazil. Chile.

\section{INTRODUÇÃO}

A importância da administração do capital circulante não é nova na literatura, de modo que vários argumentos teóricos já foram propostos para entender a relação entre o capital de giro e o desempenho das empresas (AKTAS; CROCI; PETMEZAS, 2015). Ao gerenciar o capital de giro eficientemente, as empresas podem reduzir sua dependência de financiamento externo e usar o dinheiro liberado para novos investimentos, melhorando, assim, sua situação financeira e sua flexibilidade (ALMEIDA; EID JR, 2014).

Nesse sentido, Suttapong e Tian e (2012) afirmam que as organizações estão buscando práticas inovadoras para melhorar seu desempenho e manter vantagem competitiva, bem como desenvolvendo várias técnicas, artefatos e metodologias para aperfeiçoar-se no mercado global. Dessa forma, a comparação entre o desempenho e as estratégias organizacionais é um dos instrumentos de gestão que se mostram eficazes para maximizar os resultados nos mais diversos campos de atuação.

Conforme Campos e Nakamura (2013), o objetivo primordial das empresas é elevar ao máximo seu valor aos acionistas e no mercado, enquanto que o objetivo acessório é sobreviver às oscilações no ambiente em curto prazo. Nesse contexto, uma estratégia de proteção possível é manter uma folga financeira, que consiste na manutenção da capacidade ociosa de recursos por parte da empresa, incluindo, por exemplo, capacidade produtiva não utilizada, estoques de produtos acabados ou matéria-prima, ociosidade de mão de obra especializada ou de equipamentos, excesso de caixa, contratação de linhas de crédito e capacidade de endividamento não utilizada.

As empresas que atuam no mercado de ações precisam, assim, de alternativas que possibilitem evitar perdas e garantir a maximização de retorno aos acionistas (TAVARES; SILVA, 2012). Embora as instabilidades do mercado acionário resultem em riscos e incertezas, há estudos que auxiliam os investidores na tomada de decisão, orientando-os quanto ao investimento que agregará riqueza ao acionista. Nesse cenário, as análises técnica e fundamentalista apresentam-se como artefatos gerenciais de auxílio ao investidor (PASSOS; PINHEIRO, 2009).

Um dos fatores presentes na análise fundamentalista é o estudo do desempenho financeiro, que pode ser auferido por índices financeiros. Conforme Chiarello (2014), dentre esses índices, sobressaem quatro: Price Earning Ratio (PER), Price Sales Ratio (PSR), Price Cash Dividends (PCD) e Price Book Value (PBV).

Sob essa perspectiva, alguns estudos analisaram a relação entre folga financeira e: desempenho (DANIEL et al., 2004), estrutura de capital (KIM; KIM; LEE, 2008), endividamento 
(CAMPOS; NAKAMURA, 2013), retorno por ações como informações preditivas de retornos (KIM; RITTER, 1998), rentabilidade média de ações (COSTA JR; NEVES, 2000) e criação e destruição de valor de empresas (SILVA; FERREIRA; CALEGARIO, 2009). No entanto, não foram encontrados estudos anteriores que analisaram e relacionaram a folga financeira com o retorno por ações.

Diante disso, destaca-se a seguinte questão que norteia o desenvolvimento desta pesquisa: qual a influência da folga financeira no retorno por ações em empresas brasileiras e chilenas? Nesse sentido, com o intuito de responder à questão apresentada, o objetivo deste estudo é analisar a influência da folga financeira no retorno por ações em empresas brasileiras e chilenas.

A folga financeira é importante nas empresas por fornecer flexibilidade estratégica e por ser um relevante artifício na tomada de decisão (PATZELT ET AL, 2008). Além disso, investir no mercado de ações é ariscado e gera muitas incertezas (PASSOS; PINHEIRO, 2009), motivo pelo qual este estudo é relevante. Já a escolha dos países é justificada pelo fato de que, conforme Bastos e Nakamura (2009), o Brasil e o Chile são países emergentes, tendo se tornado, após passar por grandes transformações econômicas, políticas e sociais nas últimas duas décadas, as principais e mais sólidas economias latino-americanas. Assim, de acordo com Terra (2007), o estudo nesses países se torna relevante por serem exemplos de economias emergentes que passaram por mudanças macroeconômicas em seu ambiente em um curto período de tempo. Além disso, conforme o Banco Mundial, no ano de 2014, os dois países tiveram um crescimento em seu Produto Interno Bruto (PIB) de 2,5\% em comparação com o ano anterior. Ademais, não foram identificadas pesquisas semelhantes no contexto nacional e internacional, o que assinala uma lacuna de pesquisa.

Para melhor apresentação, este estudo está estruturado em quatro seções, além desta introdutória. A seguir, é explorada a fundamentação teórica referente à temática de folga financeira e retorno por ações; posteriormente, apresenta-se a metodologia da pesquisa, seguida da análise e discussão dos dados, e, por fim, discutem-se as considerações finais.

\section{REVISÃO BIBLIOGRÁFICA}

Nesta seção, são apresentadas as principais referências acerca da folga financeira e do retorno por ações, as quais se fazem necessárias para o embasamento teórico da presente pesquisa. As bases de busca de dados bibliográficos utilizadas nesta pesquisa foram SPELL -Scientific Periodicals Electronic Library, Scopus - Document Search, Science Direct, Google Acadêmico e Portal de Periódicos Capes. As palavras utilizadas para a busca das referências foram: "folga financeira", "financial slack", "curto prazo", "modelo Fleuriet", "gestão circulante", "retorno de ações", "return per shares", "prices", "indicadores de mercado", "working capital”.

\subsection{Folga financeira}

A análise e o desenvolvimento dos conceitos de liquidez (folga) nas empresas com a finalidade de avaliar a capacidade de crédito envolvem uma gama de usuários, incluindo linhas e agências de classificação de crédito, investidores e seu gerenciamento, tendo começado a despertar mais atenção dos gestores e serem testados empiricamente na virada do século XX (BEAVER, 1966). A esse respeito, Myers e Majluf (1984) evidenciam que a soma de dinheiro em caixa, títulos e valores mobiliários caracteriza a folga financeira da empresa (poder de endividamento não utilizado), que se faz presentes quando a empresa não almeja emitir ações em curto prazo, pois a emissão dessas ações acarretaria a diminuição dos valores mobiliários da empresa. 
A organização apresenta folga em contextos normais, quando possui excesso de recursos necessários ao seu funcionamento. A folga ocorre, assim, quando os recursos existentes são superiores ao que seria suficiente para a empresa reagir frente a mudanças no ambiente em que opera (BROMILEY, 1991). Nesse sentido, como o ambiente econômico mundial constantemente passa por turbulências e mudanças, as empresas precisam definir estratégias de análises para os elementos patrimoniais de curto prazo (gestão do circulante) que proporcionem mudanças no desempenho e que permitam que se mantenham competitivas no mercado (MARQUES; BRAGA, 1995).

Quanto à gestão do capital circulante, George (2005) evidencia que existem os recursos de capital e financeiro, os quais podem ser discricionários e não discricionários. A folga de recursos financeiros que permite avaliação do capital de giro pode ser decisiva na tomada de decisão dos gestores e é usada para firmar as atividades da empresa, absorvendo o excesso de recursos durante o período de crescimento e permitindo a manutenção dos seus compromissos nos períodos de crise.

O capital de giro ou o capital circulante tem participação significativa no desempenho das empresas, por cobrir geralmente mais da metade dos ativos totais emitidos (SOUZA; FAMÁ, 1998). O capital circulante líquido (CCL) resultante do excesso de recurso de curto prazo disponível frente aos compromissos anteriormente assumidos, também de curto prazo, corresponde, assim, à folga financeira das empresas (BRAGA; NOSSA; MARQUES, 2004).

$O$ termo folga financeira indica a diferença entre os recursos totais e os pagamentos que são necessários frente às obrigações empresariais. Trata-se, assim, de uma sobra de recursos que as empresas podem utilizar de forma discricionária, tanto para combater as ameaças quanto para explorar as oportunidades (DANIEL ET AL, 2004; CLEARY, 2005; KIM; KIM; LEE, 2008).

Segundo Fusco (2006), a administração de capital de giro deve preocupar-se em administrar as várias contas patrimoniais com o objetivo de manter uma estabilidade financeira quanto ao nível de liquidez de curto prazo da empresa. Para Assaf Neto (2003), a liquidez mede a capacidade de pagamento no período assumido pela empresa, bem como a capacidade de geração e manutenção de sua posição de equilíbrio financeiro.

De acordo com Campos e Nakamura (2013), a liquidez é a capacidade de converter os ativos rapidamente em recursos monetários com o menor desconto possível em relação ao valor intrínseco deste ativo, sendo tradicionalmente relacionada ao caixa, às aplicações e aos estoques mantidos pelas empresas. Já a folga financeira é um conceito mais amplo que envolve a liquidez, mas também a capacidade da empresa de levantar novos recursos junto ao mercado financeiro.

A folga financeira, para Patzelt et al. (2008), influencia a decisão gerencial, facilita o desenvolvimento de novos produtos e o crescimento das empresas e reflete positivamente nos aspectos gerenciais relativos aos riscos. Os autores afirmam, ainda, que a folga financeira fornece às empresas uma maior flexibilidade estratégica e permite a adaptação a ambientes complexos, figurando como um importante e determinante artefato gerencial para a tomada de decisão, pois tem um impacto relevante sobre a capacidade de pagamento do empreendimento.

Nesse sentido, uma das estratégias adotadas pelas organizações para manter a estabilidade em períodos de incerteza e manter a uma solidez financeira sustentável é utilizar a folga financeira (AQUEGAWA; SOUZA; 2010). Empresas que enfrentam altas exigências, mas têm poucos recursos, orientadas para o crescimento, podem estabelecer estratégias materialmente diferentes de empresas com maior disponibilidade de recursos. Embora existam vantagens em manter uma folga financeira, o zelo demasiado pode, muitas vezes, estar associado a uma ação prejudicial, por retroceder investimentos e dificultar inovações (BEUREN; STAROSKY FILHO; KRESPI, 2013).

Daniel et al. (2004) realizaram um estudo sobre a relação entre folga financeira e desempenho utilizando uma meta-análise de 80 amostras em 66 estudos. Os resultados forneceram 
evidências de que existe uma relação positiva entre a folga e o desempenho financeiro e que essa relação é fortalecida nas empresas que possuem maiores controles relativos ao desempenho.

Kim, Kim e Lee (2008), por sua vez, investigaram a influência da estrutura de propriedade sobre a folga financeira e os investimentos em empresas coreanas no período de 1998 a 2003, utilizando a teoria da agência. As evidências encontradas no estudo indicam que a folga financeira tem uma relação invertida com os investimentos e que as diferentes estruturas influenciam essa relação.

Patzelt et al. (2008) examinaram o papel da folga financeira nas decisões de risco dos gestores relacionadas à busca de alianças estratégicas. Para isso, basearam-se em um projeto experimental com dados sobre 1.632 decisões tomadas por 51 gestores. O principal resultado obtido demonstrou que a folga financeira fornece aos gerentes a capacidade de maximizar os benefícios por meio da formação de aliança, gerando motivações aos gestores na busca de alianças estratégicas.

Campos e Nakamura (2013) pesquisaram uma proxy para folga financeira de longo prazo como uma medida de endividamento relativo a partir da distância do endividamento mediano do setor. Utilizaram, para isso, uma amostra de 65 empresas americanas de setores diferentes, compreendendo o período de 1990 a 2009. Os resultados obtidos indicam que a proxy tem uma capacidade relevante para avaliar a folga financeira - dentro do modelo de estrutura apresentado, a folga financeira apresenta poder explicativo, sugerindo desempenhar um papel dinâmico no ajuste das estruturas das empresas.

Bauren, Starosky Filho e Krespi (2014), por sua vez, analisaram a folga organizacional versus o desempenho financeiro nas empresas da BM\&FBovespa. A amostra compreendeu dados de 273 empresas no período de 2006 a 2010. Os resultados indicaram uma relação significante entre o desempenho financeiro e o critério de baixa folga e evidenciaram que o aumento da baixa folga implica aumento do desempenho financeiro, desempenho esse que, em longo prazo, contudo, apresenta uma tendência de decréscimo.

Já Aktas, Croci, Petmezas (2015) examinaram o efeito da gestão do circulante em empresas dos Estados Unidos entre 1982 e 2011. As conclusões indicam a existência da política de capital de giro em um nível ótimo e a convergência das empresas para uma condição ideal (ou aumentando ou diminuindo o seu investimento em capital de giro), para melhorar o seu estoque e, consequentemente, o seu desempenho.

\subsection{Retorno por ações}

Ao investir no mercado acionário, surge, para o investidor, a necessidade de avaliar a situação financeira das empresas em que está sendo investido, sendo os indicadores econômicofinanceiros, segundo Altman (1971), os principais artefatos para tal avaliação. Na avaliação dos investimentos, como análise de preços, taxas de retorno e valores dos títulos negociados nos mercados de capitais, destacam-se duas principais correntes denominadas de análise técnica e análise fundamentalista (SANVICENTE, 1987).

Para Povoa (2005), na análise técnica, as mais diversas informações acerca das oscilações do mercado são totalmente absorvidas, gerenciadas e repassadas a favor dos tomadores de decisões simultaneamente aos acontecimentos. Já na análise fundamentalista, obtém-se o verdadeiro valor da empresa, informação esta que é extraída por meio da verificação de todos os dados sobre a organização existentes no mercado (PINHEIRO, 2005).

A esse respeito, Tavares e Silva (2012) destacam que a análise técnica utiliza dados históricos dos ativos em determinados períodos e aprecia a tendência do investimento, possibilitando ao investidor escolher dentre o leque de opções de investimentos; enquanto que a análise 
fundamentalista se utiliza do cenário econômico e de projeções de resultados, valendo-se, também, das informações disponibilizadas nas demonstrações contábeis e de análises do mercado.

Passos e Pinheiro (2009) afirmam que, na avaliação do retorno de ações, a análise fundamentalista tem se destacado, por examinar o passado dos resultados, a gestão empresarial e as perspectivas de futuro, com o intuito de indicar a real situação da empresa. Nesse sentido, o desempenho financeiro de uma organização pode ser medido por índices financeiros, que proporcionam a constatação da eficiência ou ineficiência financeira, por meio de variáveis (SILVA; FERREIRA; CALEGARIO, 2009). A análise dos índices financeiros corrobora para maior clareza no que diz respeito não apenas à condição econômica e financeira, mas também à situação global de uma organização, o que acaba influenciando a mensuração de valores de ações no mercado de capital (SILVA; FERREIRA; CALEGARIO, 2009).Os índices de valor de mercado, relacionando o valor da ação de uma organização com seus lucros, asseguram a comparação do preço de ações entre uma organização e outra (EHRHARDT; BRIGHAM, 2012). Dentre os quatro índices de valor de mercado, destaca-se o PER, que, segundo Anderson e Brooks (2006), serve como medida amplamente utilizada para mensurar o desempenho das empresas. Para Gitman (2010), o PER, ao informar quanto os investidores estão dispostos a pagar pelo lucro da empresa, torna-se o indicador mais completo do mercado de ações.

Apesar de ser o indicador mais completo, deve-se levar em consideração que seus valores são apropriados apenas para o período a que se refere, visto que tais valores sofrem constantes oscilações com passar do tempo (ASSAF NETO, 2010). Já o PSR não sofre tanta oscilação, o que o torna mais seguro (DAMODARAN, 1997), apresentando-se como a melhor medida de avaliação individual e destacando-se como referência para futuros investidores que optam por investimentos em empresas que demonstram baixos índices de PSR (O'SHAUGHNESSY, 2005).

Quanto ao PCD, importa salientar que o crescimento esperado pode não ser alcançado, em decorrência do pagamento de elevados dividendos, o que significa menos recursos disponíveis para investimentos e, por conseguinte, desvalorização da ação (BRIGHAM; EHRHARDT, 2006). Nesse sentido, Pinheiro (2012) afirma que empresas em crescimento tendem a diminuir o índice PCD, visando reinvestir o lucro obtido em investimentos na própria empresa ao invés de pagar altos dividendos.

Por fim, no que concerne ao PBV, Damodaram (1997) afirma que, por ser o valor contábil estável, aponta dados relevantes para diagnósticos de investimentos e possibilita a comparação com o valor de mercado. Esse índice demonstra que empresas com maior valor de mercado em relação ao valor contábil são mais valorizadas e que o inverso também é verdadeiro, ou seja, que empresas com valor de mercado menor que o valor contábil são menos valorizadas (PINHEIRO, 2012).

\section{METODOLOGIA}

A fim de analisar a relação entre a folga financeira e o retorno por ações das empresas brasileiras e chilenas, realizou-se uma pesquisa que se caracteriza como descritiva, documental e quantitativa. O objetivo principal da pesquisa descritiva, segundo Gil (2002), é a descrição das características de determinada população ou fenômeno ou, então, o estabelecimento de relações entre as variáveis. Cabe ressaltar, ainda, conforme o autor, que a pesquisa descritiva observa os fatos, faz e analisa os registros e realiza a classificação e a interpretação correspondente.

Já a pesquisa documental se caracteriza pelo fato de utilizar materiais que ainda não receberam tratamento analítico, tendendo a explicar a informação bruta e tirar dela algum sentido (RAUPP; BEUREN, 2006). E a pesquisa quantitativa, conforme Marconi e Lakatos (2011), refere-se à pesquisa de atitudes e opiniões que empregam escalas que permitem sua quantificação. 
A população desta pesquisa compreendeu as companhias brasileiras listadas no IBrX-50 (Índice Brasil 50) e as chilenas listadas no IPSA-40 (Índice de Preço Seletivo de Ações) disponíveis na Base de dados Thomson ${ }^{\circledR}$. Para a análise, foram excluídas da amostra as holdings e financeiras e as empresas que não tinham os dados necessários para o estudo, de modo que a amostra foi composta de 25 empresas brasileiras e 27 chilenas, conforme evidenciado no Quadro 1.

Quadro 1 - Amostra das empresas brasileiras e chilenas

\begin{tabular}{|l|l|l|l|}
\multicolumn{2}{|c|}{ Identificação na Bolsa Empresas brasileiras } & \multicolumn{2}{l|}{ Identificação na Bolsa empresas chilenas } \\
\hline ABEV3.SA & Amber SA & ASG.SN & AES Gener SA \\
\hline BRKMS.SA & Braskem SA & AGUAa.SN & Aguas Andinas SA \\
\hline BRFS3.SA & BRF SA & ANT.SN & Antarchile SA \\
\hline CCR03.SA & CCR SA & BAN.SN & Banmedica SA \\
\hline HGTX3.SA & Cia Hering & BES.SN & Besalco SA \\
\hline PCAR4.SA & Companhia Brasileira de Distribuicao & CAP.SN & Cap SA \\
\hline SBSP3.SA & Companhia de Saneamento Basico do Estado de Sao Paulo - SABESP & CEN.SN & Cencosud SA \\
\hline CMIG4.SA & Companhia Energetica de Minas Gerais Cemig & EMB pb.SN & Coca Cola Embonor SA \\
\hline CSNA3.SA & Companhia Siderurgica Nacional & COL.SN & Colbun SA \\
\hline CSAN3.SA & Cosan SA Industria e Comercio & CCU.SN & Compania Cervecerias Unidas SA \\
\hline EMBR3.SA & Embraer SA & ECL.SN & ECL SA \\
\hline FIBR3.SA & Fibria Celulose SA & AND pb.SN & Embotelladora Andina SA \\
\hline GGBR4.SA & Gerdau SA & END.SN & Empresa Nacional de Electricidad SA \\
\hline HYPE3.SA & Hypermarcas SA & CAR.SN & Empresas CMPC SA \\
\hline KLBN4.SA & Klabin SA & COP.SN & Empresas Copec SA \\
\hline LAME4.SA Lojas Americanas SA & ENE.SN & Enersis SA \\
\hline LREN3.SA & Lojas Renner SA & FOR.SN & Forus SA \\
\hline NATU3.SA & Natura Cosmeticos SA & GAS.SN & Gasco SA \\
\hline OIBR4.SA & Oi SA & IAM.SN & Inversiones Aguas Metropolitanas SA \\
\hline CRUZ3.SA & Souza Cruz SA & LAN.SN & Latam Airlines Group SA \\
\hline SUZBS.SA & Suzano Papele Celulose SA & QNN.SN & Quinenco SA \\
\hline VIVT4.SA & Telefonica Brasil SA & RIP.SN & Ripley Corp SA \\
\hline TIMP3.SA & Tim Participacoes SA & FAL.SN & SACC Falabella \\
\hline USIM5.SA & Usinas Siderurgicas de Minas Gerais SA Usiminas & SAL.SN & SalfaCorp SA \\
\hline VALE5.SA & Vale SA & SK.SN & Sigdo Koppers SA \\
\hline & & SON.SN & Sonda SA \\
\hline & CHT.SN & Vina Concha y Toro SA \\
\hline
\end{tabular}

Fontes: dados da pesquisa.

A escolha dessa amostra ocorreu pelo fato de o IBrX-50 ser um índice que mede o retorno total de uma carteira teórica composta de 50 ações selecionadas entre as mais negociadas na BM\&FBOVESPA em termos de liquidez e pelo fato de o IPSA ser considerado o melhor indicador de resultados do mercado de ações chileno para medir os resultados das empresas de maior liquidez listadas na Bolsa de Valores de Santiago.

O período analisado compreendeu cinco anos (2010 a 2014). Bastos e Nakamura (2009) e Fama e French (1992) também estudaram a temática utilizando esse lapso temporal. De acordo com Assaf Neto (2010), esse período permite identificar a evolução da empresa nos últimos anos de maneira dinâmica.

Para obter um diagnóstico da real situação financeira das empresas, seu balanço patrimonial foi reestruturado pelo modelo Fleuriet, considerando a movimentação dinâmica e evidenciando, dessa forma, a folga financeira (ALMEIDA; EID JR 2014). Para Pires, Panhoca e Bandeira (2010), o modelo dinâmico de análise econômico-financeira permitiu que se passasse da estática análise dos indicadores de liquidez e capital de giro, para uma análise dinâmica, utilizando dados contábeis atualizados, a fim de identificar a capacidade de captação de recursos e utilizá-los para maximizar retornos. Inicialmente, esse modelo propõe uma nova classificação gerencial, ou seja, uma reorganização das contas integrantes do balanço patrimonial segundo sua natureza finan- 
ceira ou operacional, sendo essa segregação essencial para o processo de avaliação das necessidades de capital de giro (MARQUES; BRAGA, 1995; MEDEIROS; RODRIGUES, 2004).

De acordo com Souza e Bruni (2008), a reorganização das contas ocorre conforme os seus ciclos, podendo ser cíclicas (contas com ciclo operacional contínuo), não cíclicas (ciclos mais longos e de movimentação lenta) ou erráticas (contas circulantes que não estão relacionadas com a operação da empresa, indicando um movimento descontínuo). Já para Carneiro Junior e Marques (2010), tal reorganização deve se basear nos elementos de curto e longo prazo. A reclassificação das contas contábeis está evidenciada no Quadro 2.

Quadro 2: Reorganização dos grupos patrimoniais

\begin{tabular}{|c|c|}
\hline APLICAÇÃO DE RECURSOS & ORIGENS DE RECURSOS \\
\hline Ativo Circulante Financeiro (ACF) & Passivo Circulante Oneroso (PCF) \\
\hline Ativo Circulante Cíclico (ACC) & Passivo Circulante Cíclico (PCC) \\
\hline Ativo Não Circulante (ANC) & Passivo Não Circulante (PNC) \\
\hline
\end{tabular}

Fonte: adaptado de Marques e Braga (1995).

A partir dessa nova classificação do balanço patrimonial, são definidos os três componentes principais da análise dinâmica do capital de giro: a necessidade de capital de giro (NCG), o capital de giro (CDG) e o saldo de tesouraria (T) (MARQUES; SANTOS; BEUREN, 2012).

Os dados para análise foram coletados em abril de 2015 na base Thomson $^{\circledR}$ e organizados em planilhas eletrônicas, a fim de executar os cálculos das varáveis de estudo, que estão representadas no Quadro 3, a seguir.

Quadro 3 - Variáveis da pesquisa

\begin{tabular}{|c|c|c|c|}
\hline Classificação & Variável & Mensuração & Autores \\
\hline $\begin{array}{c}\text { Variável dependente } \\
\text { Folga financeira }\end{array}$ & $\begin{array}{l}\text { Necessidade de Capi- } \\
\text { tal de Giro (NCG) }\end{array}$ & $\begin{array}{l}\text { Ativo circulante cíclico - Pas- } \\
\text { sivo circulante cíclico }\end{array}$ & $\begin{array}{l}\text { Braga, Nossa e Marques } \\
\text { (2004); Marques e Braga } \\
\text { (1995); e Pires, Panhoca e } \\
\text { Bandeira (2010) }\end{array}$ \\
\hline \multirow{4}{*}{$\begin{array}{c}\text { Variáveis } \\
\text { independentes } \\
\text { Retorno por ações }\end{array}$} & $\begin{array}{lll}\text { Price } & \text { Earning } & \text { Ratio } \\
\text { (PER) } & & \end{array}$ & $\begin{array}{l}\text { Valor de Mercado das ações } \\
\text { Lucro por Ação }\end{array}$ & $\begin{array}{l}\text { Kim e Ritter (1999); Costa } \\
\text { Jr e Neves (2000); Srour } \\
\text { (2005); Alberton e Costa } \\
\text { Jr, (2007); e Passos e Pi- } \\
\text { nheiro (2009) }\end{array}$ \\
\hline & $\begin{array}{l}\text { Price Cash Dividends } \\
\text { (PCD) }\end{array}$ & $\begin{array}{l}\text { Dividendo por Ação } \\
\text { Valor de Mercado das ações }\end{array}$ & $\begin{array}{l}\text { Assaf Neto (2010); e Pi- } \\
\text { nheiro (2012) }\end{array}$ \\
\hline & $\begin{array}{l}\text { Price Book Value } \\
\text { (PBV) }\end{array}$ & $\begin{array}{l}\text { Valor de Mercado das ações } \\
\text { Valor Contábil das ações }\end{array}$ & $\begin{array}{l}\text { Kim e Ritter (1999); Costa } \\
\text { Jr e Neves (2000); Srour } \\
\text { (2005); Alberton e Costa } \\
\text { Jr, (2007); e Passos e Pi- } \\
\text { nheiro (2009) }\end{array}$ \\
\hline & $\begin{array}{l}\text { Price Sales Ratio } \\
\text { (PSR) }\end{array}$ & $\begin{array}{l}\text { Valor de Mercado das ações } \\
\text { Receita Líquida por Ação }\end{array}$ & $\begin{array}{l}\text { Kim e Ritter (1999); e } \\
\text { Brunnermeier e Nagel } \\
\text { (2013) }\end{array}$ \\
\hline
\end{tabular}

Fonte: dados da pesquisa.

Para alcançar o objetivo deste estudo, foram utilizadas a estatística descritiva e o método de regressão linear múltipla realizada por meio do software SPSS. Os resultados foram avaliados com base no $\mathrm{R}^{2}$, no $\mathrm{R}^{2}$ ajustado, no Durbin-Watson e no nível de significância do modelo.

$O R^{2}$ é utilizado para identificar o efeito da variável independente na variável dependente, configurando-se como um coeficiente de determinação e servindo como grau explicativo 
da regressão (CORRAR; PAULO; DIAS FILHO, 2011). O $\mathrm{R}^{2}$ ajustado, por sua vez, identifica a porcentagem da mutação da variável dependente que pode ser explicada pela regressão, ou seja, identifica e analisa a capacidade explicativa do modelo (DOWNING; WESTERNFIELD; BRADFORD, 1998). Já a técnica de regressão, conforme Brooks (2002), verifica a autocorrelação das falhas, analisando se os dados estão provocando distorções no desvio-padrão e no $\mathrm{R}^{2}$. $\mathrm{O}$ teste de Durbin -Watson, para atender aos preceitos da regressão, deve apresentar valores próximos a dois (HAIR JR et al., 2005) e serve para verificar a correlação entre as falhas, identificando se os resíduos próximos estão correlacionados (FIELD, 2009), ou seja, medindo o grau de confiabilidade dos dados. A seguir, consta a equação para a análise referente à finalidade da pesquisa:

$$
\begin{gathered}
\text { NCG }=\beta_{0}+\beta_{1} P E R+\beta_{2} P C D+\beta_{3} P B V+\beta_{4} P S R+\beta_{5} \text { Ano } 2010+\beta_{6} \text { Ano } 2011 \\
+\beta_{7} \text { Ano } 2012+\beta_{8} \text { Ano } 2013+\beta_{9} \text { Ano } 2014+\varepsilon
\end{gathered}
$$

A variável dependente do estudo é a folga financeira, calculada pela necessidade de capital de giro, e as variáveis independentes são compostas pelos quatro índices de retorno por ações: Índice de Preço pelas Vendas; Índice de Preço a Valor de Mercado; Índice de Preço a Valor Contábil; e Índice de Preço por Lucro.

\section{APRESENTAÇÃO E ANÁLISE DOS RESULTADOS}

Nesta seção, apresentam-se a descrição, a análise e a discussão dos resultados da pesquisa, que tem como objetivo analisar a influência da folga financeira no retorno por ações das empresas brasileiras listadas no IBrX-50 e das chilenas listadas no IPSA-40 a partir das variáveis independentes PER, PCD, PBV e PSR e da variável dependente NCG. Para isso, inicialmente, evidencia-se a análise da estatística descritiva por ano e por indicadores das empresas brasileiras e chilenas; e, em seguida, apresenta-se a regressão linear múltipla das variáveis dependentes e independentes no período de cinco anos para ambos os países em separado.

\subsection{Análises descritivas}

A fim de verificar se existe ou não relação entre folga financeira e retorno por ações nas empresas brasileiras e chilenas, realizou-se a análise descritiva das variáveis do estudo, para evidenciar a evolução dos indicadores durante o período analisado (2010 a 2014). A Tabela 1 apresenta a estatística descritiva por país e por ano.

\begin{tabular}{|c|c|c|c|c|c|c|c|c|c|c|c|c|}
\hline \multicolumn{13}{|c|}{ Empresas brasileiras } \\
\hline & \multicolumn{2}{|c|}{2010} & \multicolumn{2}{|c|}{2011} & \multicolumn{2}{|c|}{2012} & \multicolumn{2}{|c|}{2013} & \multicolumn{2}{|c|}{2014} & \multicolumn{2}{|c|}{ Total } \\
\hline & Méd. & DP & Méd. & DP & Méd. & DP & Méd. & DP & Méd. & DP & Méd. & DP \\
\hline NCG & 822,17 & $2.111,18$ & 764,96 & $2.108,83$ & 513,45 & $1.920,01$ & 646,76 & $2.450,39$ & 503,01 & $1.933,80$ & 650,07 & 2104,84 \\
\hline PBV & 3,88 & 5,07 & 4,05 & 5,01 & 4,45 & 5,66 & 3,51 & 4,05 & 3,58 & 4,09 & 3,89 & 4,78 \\
\hline PSR & 1,68 & 1,50 & 2,24 & 3,10 & 1,91 & 4,44 & 2,75 & 4,44 & 1,98 & 1,85 & 2,11 & 3,07 \\
\hline PCD & 16,67 & 37,92 & 13,82 & 15,33 & 11,22 & 9,66 & 18,65 & 39,70 & 10,23 & 5,94 & 14,12 & 21,71 \\
\hline$P / E$ & 0,03 & 0,04 & 1,58 & 1,24 & 0,03 & 0,05 & 0,04 & 0,08 & 0,04 & 0,06 & 0,34 & 0,29 \\
\hline
\end{tabular}

Tabela 1 - Estatística descritiva das variáveis das empresas brasileiras e chilenas 


\begin{tabular}{c|c|c|c|c|c|c|c|c|c|c|c|c}
\hline & \multicolumn{2}{|c|}{2010} & \multicolumn{2}{c|}{2011} & \multicolumn{2}{c|}{2012} & \multicolumn{2}{c|}{$\mathbf{2 0 1 3}$} & \multicolumn{2}{c|}{$\mathbf{2 0 1 4}$} & \multicolumn{2}{c}{ Total } \\
\cline { 2 - 13 } & Méd. & DP & Méd. & DP & Méd. & DP & Méd. & DP & Méd. & DP & Méd. & DP \\
\hline NCG & $1.038,20$ & $3.878,16$ & $1.205,44$ & $4.463,10$ & $1.388,77$ & $5.651,84$ & $1.300,44$ & $5.557,47$ & $1.163,09$ & $4.785,43$ & $2.849,61$ & $3.265,97$ \\
PBV & 2,92 & 1,54 & 2,73 & 1,50 & 2,52 & 1,52 & 1,86 & 1,03 & 1,89 & 1,21 & 1,95 & 1,76 \\
PSR & 2,00 & 1,14 & 1,84 & 1,15 & 1,90 & 1,36 & 1,46 & 1,14 & 1,42 & 1,18 & 1,49 & 1,40 \\
PCD & 14,72 & 9,05 & 19,53 & 19,67 & 20,00 & 33,69 & 19,90 & 38,30 & 19,78 & 38,30 & 21,63 & 24,25 \\
P/E & 0,03 & 0,03 & 0,03 & 0,03 & $-0,02$ & 0,26 & 0,03 & 0,04 & 0,02 & 0,05 & 0,02 & 0,08 \\
\hline
\end{tabular}

Fonte: dados da pesquisa.

Com base na Tabela 1, observa-se que a média da NCG nas empresas brasileiras é menor que nas empresas chilenas entre 2010 e 2014, o que indica que as empresas do Chile têm maior folga financeira que as empresas do Brasil. Tais dados vão de encontro aos achados de Leite, Guse, Silva (2014), em que as empresas brasileiras obtiveram médias de desempenho superior que as empresas chilenas. Já quanto à média, todas as empresas estão com boa dinâmica de capital de giro, porque, conforme Marques e Braga (1995), a NCG positiva indica que as empresas conseguem fazer frente a todas as suas obrigações que e ainda sobra uma parcela para utilizarem como vantagem competitiva em tempos de crises ou para reinvestir, lembrando que a NCG no modelo Fleuriet é resultado da subtração do ativo circulante cíclico pelo passivo circulante cíclico (MARQUES; BRAGA, 1995; PIRES; PANHOCA; BANDEIRA, 2010).

Mas nem sempre possuir uma folga financeira elevada resulta em melhor desempenho organizacional ou de mercado, pois isso depende de como as empresas irão gerenciar esses recursos. Conforme Souza e Bruni (2008), as alterações que ocorrem na NCG são relativas a modificações presentes no ambiente econômico em que as empresas estão inseridas. Então, não se pode afirmar que, quanto maior for a folga, melhor será o retorno, o que não corrobora os achados de Aktas, Croci, Petmezas (2015), que evidenciaram que um bom nível de folga (capital de giro) melhora o desempenho das empresas, e o estudo de Bauren, Starosky Filho e Krespi (2014), no qual houve uma relação significante entre o desempenho e o critério de baixa folga. Essa situação fica evidente na análise dos indicadores de retorno por ações, já que, de acordo com Ehrhardt e Brigham (2012), os índices de valor de mercado relacionam o valor da ação com lucros, permitindo comparar o preço de ações entre as organizações.

Nota-se que, em relação aos indicadores de mercado, as empresas chilenas têm maior retorno somente no índice PCD, com média de 21,63, contra 14,12 de média das empresas brasileiras. Isso indica que, na média, as empresas brasileiras proporcionam maiores retornos para seus acionistas do que as empresas chilenas, mesmo apresentando menor folga financeira, 0 que vai de encontro ao estudo de Guse et al. (2014), que evidenciaram que as empresas do Chile tiveram um maior retorno em relação às empresas do Brasil. Uma explicação para esse fato, segundo Martinsons e Davison (2007), é que as empresas chilenas costumam manter decisões mais centralidades e arbitrárias, não arriscando muito no mercado de ações, o que vai de encontro ao que Afonseca e Viera (2007) relataram, para quem as empresas do Chile têm uma cultura organizacional diferente do Brasil, sendo mais flexíveis e criativas, conseguindo se adaptar melhor às condições de mercado que os brasileiros e, muitas vezes, obtendo um retorno também melhor.

Analisando o desvio-padrão, variação em relação à média das variáveis do estudo, percebe-se que a variável NCG apresenta variação significativa em todos os anos, o que demonstra que a folga financeira das empresas brasileiras pertencentes ao $\mathrm{IBrX}-50$ e das empresas chilenas pertencentes ao IPSA-40 apresenta alta variação no período analisado. Já nos índices de valor de mercado, o desvio-padrão ficou mais próximo da média, indicando que, na média, não houve muita diferença no retorno por ações das empresas analisadas. 


\subsection{Regressão linear múltipla}

Em uma segunda etapa da pesquisa, foram elaboradas duas regressões lineares múltiplas, utilizando os mesmos testes estatísticos: uma para as empresas do Brasil e outra para as empresas do Chile. Os resultados foram avaliados com base no $\mathrm{R}^{2}$, no $\mathrm{R}^{2}$ ajustado, no Durbin-Watson e no nível de significância do modelo.

A Tabela 2, exposta a seguir, evidencia as regressões lineares múltiplas das empresas brasileiras, permitindo verificar se existe influência (positiva, negativa ou nula) da folga financeira no retorno por ações. Ressalta-se que, segundo Campos e Nakamura (2013), a folga financeira envolve a liquidez e a capacidade da empresa de levantar novos recursos junto ao mercado financeiro.

Tabela 2 - Resultado do modelo de regressão linear das empresas brasileiras

\begin{tabular}{|c|c|c|}
\hline \multirow[t]{2}{*}{ Variáveis } & \multicolumn{2}{|c|}{$\begin{array}{c}\text { Regressão Linear Múltipla - Brasil } \\
\text { Necessidade de Capital de Giro (NCG) }\end{array}$} \\
\hline & Coeficiente & Significância \\
\hline (Constante) & 1077,28 & 0,00 \\
\hline Price Earning Ratio (PER) & $-77,98$ & $0,05^{*}$ \\
\hline Price Cash Dividends (PCD) & $-89,80$ & 0,22 \\
\hline Price Book Value (PBV) & 1,24 & 0,87 \\
\hline Price Sales Ratio (PSR) & 141,30 & 0,53 \\
\hline $\mathrm{R}^{2}$ & \multicolumn{2}{|c|}{0,06} \\
\hline $\mathrm{R}^{2}$ ajustado & \multicolumn{2}{|c|}{0,03} \\
\hline Durbin-Watson & \multicolumn{2}{|c|}{2,18} \\
\hline Sig. & \multicolumn{2}{|c|}{0,11} \\
\hline
\end{tabular}

*Significativo ao nível de $5 \%$. Fonte: dados da pesquisa.

De acordo com os resultados evidenciados na Tabela 2, o $\mathrm{R}^{2}$ indica que as variáveis independentes são responsáveis por $6 \%$ da variação da NCG, o que aponta para a não confiabilidade do modelo, embora o resultado do teste Durbin-Watson aponte para a sua confiabilidade. Como o modelo não ficou significante ao nível de $5 \%$, isso indica que a NCG não é significante para avaliar o retorno das ações das empresas brasileiras.

Ainda conforme dados da Tabela 2, a única variável independente que apresentou significância e influência negativa na folga financeira foi o PER, o que corrobora os achados de Anderson e Brooks (2006) e Gitman (2010), que indicam que esse índice se destaca em relação aos demais três índices de valor de mercado no desempenho de empresas, sendo muito utilizado para medir e informar quanto os investidores estão dispostos a pagar pelo lucro da empresa. Os demais indicadores, PCD, PBV e PSR, não apresentaram relevância no modelo, indicando que a NCG não sofre influência desses indicadores.

No entanto, de acordo com os dados evidenciados na Tabela 3, que analisa os resultados da regressão linear múltipla nas empresas chilenas, nenhum dos quatro indicadores do retorno por ações influenciam (negativamente ou positivamente) a folga financeira das empresas da amostra. 
Tabela 3 - Resultado do modelo de Regressão Linear das empresas chilenas

\begin{tabular}{|c|c|c|}
\hline \multirow[t]{2}{*}{ Variáveis } & \multicolumn{2}{|c|}{$\begin{array}{c}\text { Regressão Linear Múltipla - Chile } \\
\text { Necessidade de Capital de Giro (NCG) }\end{array}$} \\
\hline & Coeficiente & Significância \\
\hline (Constante) & 3079,70 & 0,00 \\
\hline Price Earning Ratio (PER) & $-516,67$ & 0,11 \\
\hline Price Cash Dividends (PCD) & $-525,60$ & 0,17 \\
\hline Price Book Value (PBV) & 11,31 & 0,41 \\
\hline Price Sales Ratio (PSR) & 3034,66 & 0,23 \\
\hline $\mathrm{R}^{2}$ & \multicolumn{2}{|c|}{0,07} \\
\hline $\mathrm{R}^{2}$ ajustado & \multicolumn{2}{|c|}{0,04} \\
\hline Durbin-Watson & \multicolumn{2}{|c|}{2,25} \\
\hline Sig. & \multicolumn{2}{|c|}{0,05} \\
\hline
\end{tabular}

*Significativo ao nível de $5 \%$.

Fonte: dados da pesquisa.

Conforme os dados evidenciados na Tabela 3, o $\mathrm{R}^{2}$ resultou em $7 \%$, o que demonstra que os indicadores de retorno por ações não são influenciados pela NCG (folga financeira) nas empresas chilenas. Os resultados da análise de regressão linear nessas empresas sugeriram que nenhuma das variáveis independentes (PER, PCD, PBV e PSR) apresentam influência significante sobre a variável dependente (NCG), indicando que o retorno por ações não influencia a folga financeira das empresas chilenas.

Dentro do modelo de regressão linear utilizado, a folga financeira não apresenta poder explicativo ou influência sobre os índices de valor de mercado. Conforme evidenciado na justificativa deste estudo, não foram encontradas pesquisas relacionando a folga financeira com o retorno por ações. No entanto, a folga financeira apresenta uma relação positiva com outros indicadores, como demonstrado por Daniel et al. (2004), que evidenciaram que, quanto maior for a folga financeira, maior será o desempenho financeiro da empresa. Tal resultado não condiz com os resultados desta pesquisa, em que o país com maior folga não apresentou o maior retorno. Já Kim, Kim e Lee (2008) demonstraram que a estrutura da empresa é influenciada pela folga financeira, o que vai do encontro dos achados de Campos e Nakamura (2013), para quem a folga financeira apresenta poder explicativo em relação à estrutura das empresas.

\section{CONSIDERAÇÕES FINAIS}

Este estudo teve como objetivo analisar a influência da folga financeira no retorno por ações das empresas brasileiras e chilenas listadas no IBrX-50 e IPSA-40, respectivamente. A amostra analisada compreendeu 25 empresas brasileiras e 27 empresas chilenas em um período de cinco anos (2010 a 2014).

Os resultados evidenciaram que as empresas brasileiras possuem menor folga financeira do que as empresas chilenas. No entanto, as empresas do Brasil apresentaram índices de retornos por ações melhores, o que sugere que nem sempre as empresas com maior folga terão melhores retornos de mercado.

$\mathrm{Na}$ análise das empresas brasileiras, notou-se, ainda, que, dentre as variáveis independentes analisadas, a PER influencia negativamente a folga financeira e que as demais variáveis não influenciam o retorno por ações na NCG. Já nas empresas chilenas, não houve influência significante da folga financeira no retorno por ações em nenhum dos indicadores, o que sugere que não há influência das variáveis independentes sobre a variável dependente. 
Nesse sentido, pode-se concluir que, nas empresas brasileiras, considerando-se o período analisado, o PER influencia negativamente a folga financeira, de modo que, quanto maior for o PER, menor será a NCG, e que os indicadores PCD, PBV e PSR não influenciam significantemente a folga financeira. Já nas empresas chilenas, todos os índices, PER, PCD, PBV e PSR, não influenciam a folga financeira. Isso demonstra uma pequena diferença entre a análise das empresas brasileiras e chilenas, visto que, nas empresas brasileiras, o PER influenciou negativamente a folga financeira, enquanto que, nas empresas chilenas, a folga financeira não sofreu influência desse e de nenhum outro índice de mercado analisado.

Notam-se, contudo, algumas limitações desta pesquisa, como o fato de os testes $R^{2} \mathrm{e}$ $\mathrm{R}^{2}$ ajustado do modelo, tanto para empresas brasileiras quanto para empresas chilenas, terem apresentado valores baixos: $R^{2}$ de $6 \%$ e $R^{2}$ ajustado de $3 \%$ (nas empresas brasileiras) e $R^{2}$ de $7 \%$ e $\mathrm{R}^{2}$ ajustado de $4 \%$ (nas empresas chilenas). Outra limitação é a amostra utilizada, já que, devido à ausência de alguns dados e à exclusão de holdings e empresas financeiras, a amostra foi composta de 25 empresas brasileiras e 27 chilenas, fato que acabou gerando no modelo analisado uma baixa significância na correlação das variáveis estudadas.

Apesar das limitações, este estudo é significante por preencher uma lacuna de pesquisa identificada na revisão literária e exposta na fundamentação teórica. A contribuição deste estudo consiste, assim, em analisar a influência da folga financeira no retorno de ações, visto que não existiam pesquisas a esse respeito.

Por fim, para estudos futuros, sugere-se utilizar uma amostra maior, para empresas tanto brasileiras quanto chilenas, empregando o mesmo modelo e análise das significâncias da correlação dos dados no programa SPSS, a fim de aumentar a significância da amostra e, assim, confirmar ou contrariar as limitações e os achados desta pesquisa. Outra possibilidade seria buscar formas distintas de analisar a influência da folga financeira no retorno por ações, que não seja pela regressão linear utilizada neste estudo, bem como comparar o mercado brasileiro com outros mercados correlatos.

\section{REFERENCIAS}

AKTAS, Nihat; CROCl, Ettore; PETMEZAS, Dimitris. Is working capital management valueenhancing? Evidence from firm performance and investments. Journal of Corporate Finance, v. 30, p. 98-113, 2015.

ALTMAN, Edward I. Railroad bankruptcy propensity. The Journal of Finance, v. 26, n. 2, p. 333-345, 1971.

ANDERSON, Keith; BROOKS, Chris. The LongTerm Price-Earnings Ratio. Journal of Business Finance \& Accounting, v. 33 , n. 7-8, p. 10631086, 2006.

AQUEGAWA, Haroldo Paulo; SOUZA, Emerson Santana de. Sustentabilidade financeira a partir dos índices de liquidez e ciclo financeiro: uma análise setorial do portfólio ISE frente à crise de 2008. 2010.

ASSAF NETO, Alexandre; SILVA, César Augusto Tibúrcio. Administração do Capital de Giro. 3a Ed. São Paulo. Ed. Atlas, 2002.

ASSAF NETO, Alexandre. Finanças corporativas e valor. 5. ed. São Paulo: Atlas, 2010.

BANCO MUNDIAL. World Bank national accounts data, and OECD National Accounts data files. Disponível em: <http://www. worldbank.org/en/publication/globaleconomicprospects $/$ data? region $=$ LAC.> Acesso em: 28 jul. 2015.

BRAGA, Roberto; NOSSA, Valcemiro; MARQUES, José Augusto Veiga da Costa. Uma proposta para a análise integrada da liquidez e rentabilidade das empresas. Revista 
Contabilidade \& Finanças, v. 15 , n. especial, p. 51-64, 2004.

BASTOS, Douglas Dias; NAKAMURA, Wilson Toshiro. Determinantes da estrutura de capital das companhias abertas no Brasil, México e Chile no período 2001-2006. Revista Contabilidade \& Finanças-USP, v. 20, n. 50, p. 75-94, 2009.

BEAVER, William H. Financial ratios as predictors of failure. Journal of accounting research, v. 4, p. 71-111, 1966.

BRIGHAM, Eugene; EHRHARDT, Michael. Administração financeira: teoria e prática. São Paulo: Thomson, 2006.

BROOKS, Cris. Introductory Econometrics for Finance. New York: Cambridge University Press, 2002.

BROMILEY, Philip. Testing a causal model of corporate risk taking and performance. Academy of Management journal, v. 34, n. 1, p. 37-59, 1991.

BUEREN, Ilse Maria; STAROSKYFILHO, Loriberto; KRESPI, Nayane Thais. Folga organizacional versus desempenho financeiro Um estudo nas empresas da BM \& FBovespa. Contaduría y Administración: Revista Internacional, v. 59, n. 2, 2014.

CAMPOS, Anderson; NAKAMURA, Wilson Toshiro. Folga Financeira Avaliada como Endividamento Relativo e Estrutura de Capital. Revista de Finanças Aplicadas, v. 1, p. 1-19, 2013.

CARNEIRO JUNIOR, João Bosco Arbués; MARQUES, José Augusto Veiga da Costa. Uma avaliação crítica dos modelos dinâmicos de curto prazo e sua integração à análise vertical da demonstração das origens e aplicações de recursos. Revista de Contabilidade do Mestrado em Ciências Contábeis da UERJ, v. 10, n. 1, p. 91-108, 2010.

CHIARELLO, Tânia Cristina. Influência da estrutura de capital e da política de dividendos no desempenho financeiro de empresas familiares brasileiras e chilenas, 2014. $140 \mathrm{f}$. Dissertação (Mestrado em Ciências Contábeis) - Universidade Regional de Blumenau, Blumenau, 2014.

CLEARY, Sean. Corporate investment and financial slack: international evidence. International Journal of Managerial Finance, v. 1, n. 3, p. 140-163, 2005.

CORRAR, Luiz J; PAULO, Edilson; DIAS FILHO José Maria. Análise multivariada: para os cursos de administração, ciências contábeis e economia. 5. ed. São Paulo: Atlas, 2011.

DA SILVA, Júlio Orestes et al. Nível informacional entre a análise tradicional e avançada do capital de giro. Revista Pretexto, v. 13, n. 2, 2012.

DAMODARAN, Aswath. Avaliação de investimentos: ferramentas e técnicas para a determinação do valor de qualquer ativo. Rio de Janeiro: Qualitymark, 1997.

DANIEL, Francis; LOHRKE, Franz; FORNACIARIC, Charles; TURNER JR, Andrew. Slack resources and firm performance: a meta-analysis. Journal of Business Research, v. 57, n. 6, p. 565-574, 2004.

DE AFÔNSECA, Suzana Melgaço; VIEIRA, Adriane. A gestão da cultura organizacional de uma empresa multinacional: Brasil $X$ Chile. Revista de Administração FEAD, v. 4, p. 103120, 2007.

DE ALMEIDA, Juliano Ribeiro; EID, William. Access to finance, working capital management and company value: Evidences from Brazilian companies listed on BM\&FBOVESPA. Journal of Business Research, v. 67, n. 5, p. 924-934, 2014.

DE SOUZA, Milanez Silva; FAMÁ, Rubens. Gestão do Capital de Giro na Corporação Virtual. Contabilidade Vista \& Revista, v. 9, n. 2, p. 15-30, 1998. 
DE SOUZA, Sandra Marinho; BRUNI, Adriano Leal. Risco de crédito, capital de giro e solvência empresarial: um estudo na indústria brasileira de transformação de cobre. Revista Universo Contábil, v. 4, n. 2, p. 59-74, 2008.

DOWNING, D., WESTERNFIELD , R.W.; BRADFORD, D.J. Princípios da administração financeira. São Paulo: Saraiva, 1998.

EHRHARDT, Michal C.; BRIGHAM, Eugene F. Administração Financeira: teoria e prática. 13. ed. São Paulo: Cengage Learning, 2012.

FIELD, Andy. Descobrindo a estatística usando o SPSS. 2. ed. São Paulo: Artmed, 2009.

FUSCO, José Paulo Alves. Necessidade de capital de giro e nível de vendas. Revista de Administração de Empresas, v. 36, n. 2, p. 5366, abr./jun. 1996.

GEORGE, Gerard. Slack resources and the performance of privately held firms. The Academy of Management Journal, v. 48, n. 4, 2005.

GITMAN, Lawrence Jeffrey. Princípios de administração financeira. 10. ed. São Paulo: Addison Wesley, 2004.

GITMAN, Lawrence Jeffrey. Princípios de administração financeira. 12. ed. São Paulo: Pearson, 2010.

GUSE, Jaqueline Carla et al. Analysis of financial and economic performance technology companies leveraging information brazilian and chilean. In: INTERNATIONAL CONFERENCE ON INFORMATION SYSTEMS AND TECHNOLOGY MANAGEMENT, 11, 2014, São Paulo. Anais... São Paulo: FEA-USP, 2014. p 1573-1595.

HAIR JR., Joseph F.; ANDERSON, Rolph E.; TATHAM, Ronald L; BLACK, Willian C. Análise multivariada de dados. 5. ed. São Paulo: Bookman, 2005.

KIM, Hicheon; KIM, Heechun; LEE, Peggy M. Ownership structure and the relationship between financial slack and R\&D investments: Evidence from Korean firms. Organization Science, v. 19, n. 3, p. 404-418, 2008.

LEITE, Maurício; GUSE, Jaqueline Carla; SILVA, Tarcísio Pedro. Análise de desempenho econômico financeiro de empresas de logística brasileiras e chilenas. In: SIMPÓSIO DE ADMINISTRAÇÃO DA PRODUÇÃO, LOGÍSTICA E OPERAÇÕES INTERNACIONAIS, 7, 2014, São Paulo. Anais... FGV-EAESP, 2014.

MARCONI, Marina de Andrade; LAKATOS, Eva Maria. Técnicas de pesquisa: planejamento e execução de pesquisas, amostragens e técnicas de pesquisa, análise e interpretação de dados. São Paulo: Atlas, 2011.

MARQUES, José Augusto Veiga da Costa; BRAGA, Roberto. Análise dinâmica do capital de giro: o modelo Fleuriet. RAE-Revista de Administração de Empresas, v. 35, n. 3, p. 4963, 1995.

MARQUES, Leandro; DOS SANTOS, Vanderlei; BEUREN, Ilse Maria. Abordagem dinâmica do capital de giro em artigos publicados nos periódicos nacionais do Qualis CAPES. Revista de Economia e Administração, v. 11, n. 1, 2012.

MAROCO, João; BISPO, Regina. Estatística aplicada às ciências sociais e humanas. 2003.

MARTINSONS, Maris G.; DAVISON, Robert M. Strategic decision making and support systems: Comparing American, Japanese and Chinese management. Decision Support Systems, v. 43, n. 1, p. 284-300, 2007.

MEDEIROS, Otávio Ribeiro de; RODRIGUES, Fernanda Fernandes. Questionando empiricamente a validade do Modelo Fleuriet. Revista de Administração e Contabilidade da Unisinos, p. 25-32, 2004.

MYERS, Stewart C.; MAJLUF, Nicholas S. Corporate financing and investment decisions when firms have information that investors do not have. Journal of financial economics, v. 13, 
n. 2, p. 187-221, 1984.

PATZELT, Holger; SHEPHERD, Dean A. DEEDS, David; BRADLEY, Steven W.. Financial slack and venture managers' decisions to seek a new alliance. Journal of Business venturing, v. 23, n. 4, p. 465-481, 2008.

PINHEIRO, Juliane Lima. Mercado de Capitais. 3.ed. São Paulo: Atlas, 2005.

PINHEIRO, Juliane Lima. Mercado de capitais: fundamentos e técnicas. 6. ed. São Paulo: Atlas, 2012.

PIRES, Eder Alexandre; PANHOCA, Luiz; DA ROCHA BANDEIRA, Goubert Laertes. Análise da influência do modelo dinâmico na geração de valor econômico agregado nas empresas calçadistas listadas na Bovespa nos anos de 2005, 2006 e 2007. Revista Gestão Organizacional, v. 3, n. 2, p. 225-237, 2010.

PÓVOA, Alexandre. Valuation: como precificar ações. São Paulo: Globo, 2004.

O'SHAUGHNESSY, James P. What works on Wall Street. 3. ed. New York: McGraw-Hill, 2005.

REILLY, Frank K.; BROWN, Keith C. Investment analysis and portfolio management. 7. ed. Cincinnati: Thomson-South Western, 2003.

SANVICENTE, Antonio Zoratto. Como fazer e como não fazer uma análise dos fundamentos dos valores de ações ordinárias. Revista de Administração da Universidade de São Paulo, v. 19, n. 2, 1984.

SILVA, Sabrina Soares da; FERREIRA, Patrícia Aparecida; CALEGARIO, Cristina Lelis Leal. Estratégias financeiras empresariais para criação e destruição de valor. Revista GESTÃo. Org, v. 7, n. 3, p. 348-362, 2009.

SUTTAPONG, Ketsaraporn; TIAN, Zhilong. Performance Benchmarking for Building Best Practice in Small and Medium Enterprises (SMEs). International Journal of Business and
Commerce, v. 1, n. 10, p. 46-60, 2012.

TAVARES, Adilson de Lima; SILVA, César Augusto Tibúrcio. A análise financeira fundamentalista na previsão de melhores e piores alternativas de investimento. Revista Universo Contábil, v. 8, n. 1, p. 37-52, 2012.

TERRA, Paulo Renato Soares. Estrutura de capital e fatores macroeconômicos na América Latina. Revista de Administração, v. 42, n. 2, p. 192-204, 2007. 